\title{
Numerical forecast and analysis of a tropical-like cyclone in the Ionian Sea
}

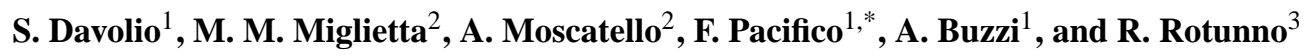 \\ ${ }^{1}$ Institute of Atmospheric Sciences and Climate, ISAC - CNR, Bologna, Italy \\ ${ }^{2}$ Institute of Atmospheric Sciences and Climate, ISAC - CNR, Lecce, Italy \\ ${ }^{3}$ National Center for Atmospheric Research (NCAR is sponsored by the National Science Foundation), \\ Boulder, Colorado, USA \\ *now at: School of Geographical Science, University of Bristol, Bristol, UK; Met Office Hadley Centre, Exeter, UK
}

Received: 3 September 2008 - Revised: 23 January 2009 - Accepted: 25 March 2009 - Published: 3 April 2009

\begin{abstract}
A forecasting system has been implemented for operational weather prediction over southern Italy in the framework of the RISKMED (INTERREG IIIB) project, which aims at weather-risk reduction in the central and eastern Mediterranean area. The system comprises two different regional forecasting chains, one based on BOLAM and MOLOCH models, the second based on the Weather Research and Forecasting (WRF) model.

On 26 September 2006, a subsynoptic-scale vortex developed over the Mediterranean Sea and affected south-eastern Italy. The cyclone was documented by radar reflectivity maps, Meteosat Second Generation satellite images and surface stations data. The observational analysis showed that the cyclone possessed the typical characteristics of a Mediterranean tropical-like cyclone.

All the limited-area models employed in RISKMED were able to properly forecast the formation of the small-scale vortex, although with differences in intensity, trajectory and evolution. The predictability of the event has been evaluated employing a multi-model, multi-analysis approach. The simulation results show strong sensitivity to the specification of the initial and boundary conditions.

Sensitivity experiments were performed in order to analyse the mechanisms responsible for the development and the maintenance of the cyclone over the sea. The life cycle of the vortex turned out to be characterized by different phases: the orographic cyclogenesis on the lee side of the Atlas Mountains; the initial phase of development, characterised by the
\end{abstract}

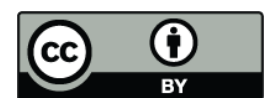

Correspondence to: S. Davolio (s.davolio@isac.cnr.it) critical role played by the surface heat fluxes; the transition to a tropical-like cyclone mainly as a consequence of the latentheat release associated with strong convective activity over the Ionian Sea; finally, the maintenance of the vortex strength due to both the surface fluxes and the release of latent heat.

\section{Introduction}

Due to its peculiar morphology, physiographic characteristics and geographical location, the Mediterranean basin is an area prone to high-impact weather events, such as heavy precipitation or intense cyclogenesis and cyclones often associated with wind storms, floods, high waves and storm surges, which can adversely impact human activities leading to economic damages and even casualties. Therefore, accurate prediction of hazardous weather conditions is a very important issue in the Mediterranean region.

The main objective of the European project RISKMED (INTERREG III B) was to set up an early-warning system for severe-weather events, aimed at predicting the weather risk in the central and eastern Mediterranean area a few days in advance. In order to provide information to the warning system, two weather-prediction chains were implemented over southern Italy (in particular Calabria and Apulia) with the purpose of producing operational high-resolution forecasts up to $72 \mathrm{~h}$.

The two modelling systems used were the hydrostatic model BOLAM together with the non-hydrostatic model MOLOCH, which is one-way nested in BOLAM twelve hours after initialization, and the non-hydrostatic model WRF/ARW, version 2.2, implemented in a two-way nesting

Published by Copernicus Publications on behalf of the European Geosciences Union. 


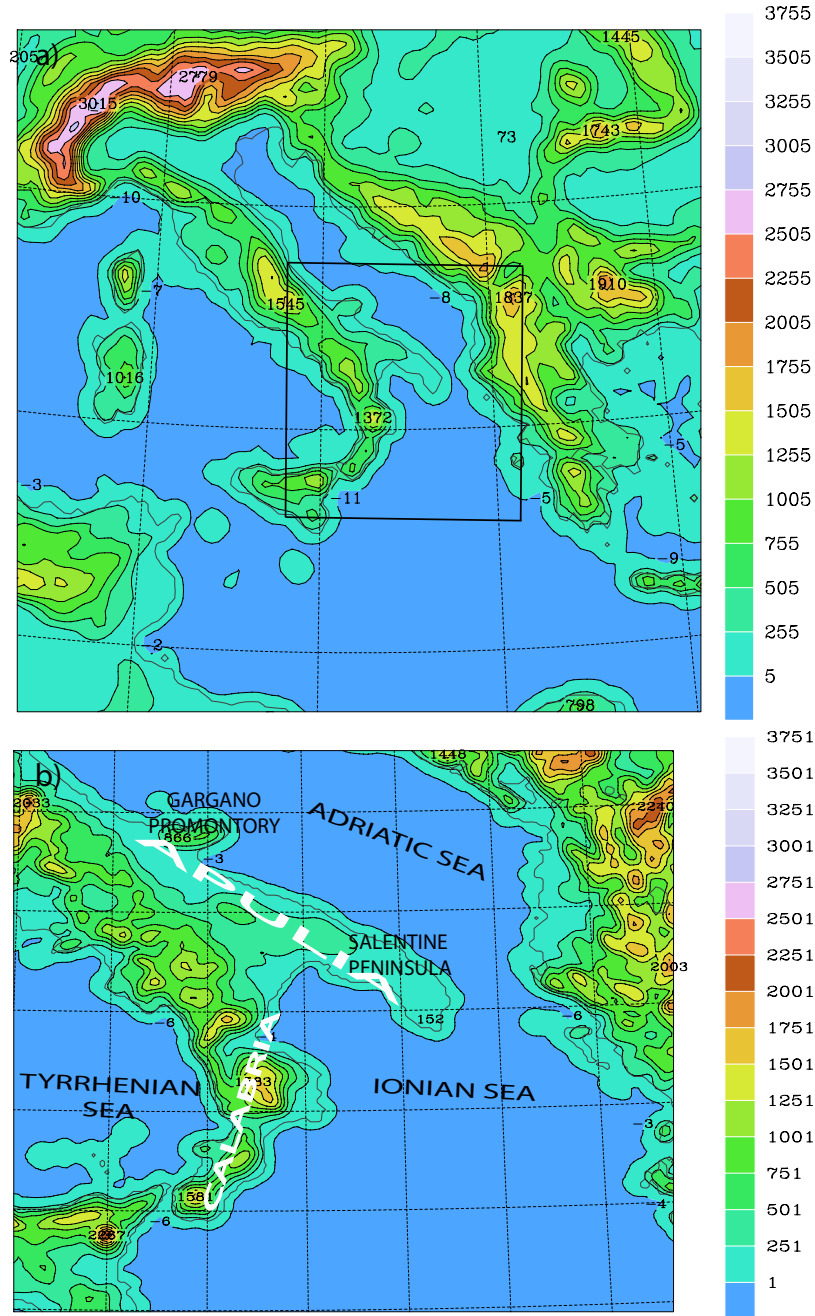

Fig. 1. Integration domains and orography for coarse (BOLAM) and high-resolution (MOLOCH) forecasts. Similar domains are used for the WRF model. The rectangular box in (a) indicates the high-resolution domain displayed in (b).

configuration (for the model descriptions see Davolio et al., 2007 and Skamarock et al., 2005, respectively). For the low-resolution integration (BOLAM and WRF outer grid) moist convection is parameterized, while for the higher resolution grid (MOLOCH and WRF inner grid) the deepmoist-convection parameterization is switched off. The model configurations were selected taking into account the requirements of the early-warning system, the constraint due to available computational resources and the need for model inter-comparison. As a consequence, similar domains (Fig. 1) and almost the same resolutions were chosen for the two modelling systems, as shown in Table 1. For the operational activity, initial and boundary conditions were provided by GFS-NCEP global model analyses and forecasts (at three-hour intervals) at $0.5^{\circ} \times 0.5^{\circ}$ resolution, starting at 00:00 UTC every day. Sensitivity experiments (see Sect. 4) were performed using also ECMWF global-model analysis and forecasts at $0.25^{\circ} \times 0.25^{\circ}$ resolution. Sea surface temperature is provided by the global model analyses, after a suitable interpolation that avoids contamination between land and sea temperature values.

During the pre-operational phase of the project, on 26 September 2006, an intense mesoscale vortex displaying features typical of tropical cyclones, although on a much smaller scale, affected the target area. The formation of this vortex was forecast by the RISKMED models, although with differences in intensity, evolution and trajectory, as discussed in this paper. Since this kind of phenomena, known as a tropical-like cyclone (TLC hereinafter; Billing et al., 1983) or Mediterranean hurricanes - "Medicanes" - (Emanuel, 2005), are observed only occasionally over the Mediterranean basin (Lagouvardos et al., 1999; Pytharoulis et al., 2000; Fita et al., 2007) and the mechanisms leading to their intensification are not yet fully understood, this event represented an opportunity to explore different aspects related to dynamics and forecasting of this TLC. Model simulations allow for the investigation of the physical mechanisms responsible for its formation and deepening, and in particular, the relative role of surface-heat flux and latent-heat release associated with deep convection through the life cycle of the TLC. The event also provides an opportunity to assess the ability of state-of-the-art models to properly forecast the development and path of the cyclone and to evaluate its predictability, since a (although low-dimensional) multimodel and multi-analysis forecasting system is available. In the present paper attention will be mainly focused on the BOLAM-MOLOCH simulations, since the main results obtained with WRF have been already presented in a companion study (Moscatello et al., 2008a).

This paper is organized as follows. Section 2 provides an overview of the event through an observational analysis and a discussion of the control simulation. Section 3 is devoted to a predictability analysis. Section 4 describes the sensitivity experiments aimed at understanding the role of surface fluxes and latent-heat release during the vortex life cycle. Finally concluding remarks are drawn in Sect. 5.

\section{Analysis of the event}

\subsection{Observational evidence}

The synoptic situation prior to the development of the TLC is displayed in Fig. 2. The GFS analysis at 12:00 UTC, 25 September 2006, interpolated to the BOLAM grid, shows a baroclinic cyclone, which was deepening over the Tyrrhenian Sea, associated with an upper-level trough in the middle troposphere elongated over the Mediterranean basin towards northern Africa. Between Tunisia and Sicily a secondary and weaker cyclonic disturbance was slowly deepening as it moved across the Strait of Sicily. Moscatello 
Table 1. Model simulation domain characteristics.

\begin{tabular}{lllll}
\hline Model & $\begin{array}{l}\text { Horizontal } \\
\text { Resolution }(\mathrm{km})\end{array}$ & Grid Points & Vertical Levels & $\begin{array}{l}\text { Centre } \\
(\text { Lon,Lat })\end{array}$ \\
\hline BOLAM & 16 & $103 \times 103$ & 40 & $16.10,40.40$ \\
MOLOCH & 3.8 & $150 \times 162$ & 50 & $17.10,39.79$ \\
WRF-g1 & 16 & $108 \times 108$ & 31 & $16.18,40.04$ \\
WRF-g2 & 4 & $129 \times 153$ & 31 & $17.46,39.96$ \\
\hline
\end{tabular}

et al. (2008a) showed that this low-pressure system originated during the night between 24 and 25 September as an orographic cyclone (Tibaldi et al., 1990) on the lee side of the Atlas Mountains, as a consequence of the interaction between the above mentioned trough and the orography. The transition of the relatively large orographically generated cyclone into a much smaller-scale vortex through the action of convection along the Strait of Sicily presents similarities with the transformation of a weakly rotating flow into a tropical cyclone and in particular with the "hot tower" hypothesis put forward by Montgomery et al. (2006), in the sense that strong and probably rather undiluted convective updrafts develop in a nucleus of pre-existing high cyclonic vorticity. Subsequently, the vortex moved north-eastward driven by the midtropospheric flow associated with the low-pressure system located over the Tyrrhenian Sea and entered the Ionian Sea following a trajectory almost parallel to the Calabrian coast. In the early morning of 26 September, the cyclone, associated with a warm tongue in the low troposphere, quickly intensified and then reached (at about 09:00 UTC) and crossed the Salentine Peninsula, i.e. the region near the tip of southeastern Italy (Fig. 1b).

The transit of the cyclone over an area characterized by the presence of a high-resolution surface-station network and two meteorological radars, together with the availability of high-resolution satellite images, allowed for a detailed observational analysis. Moscatello et al. (2008b) determined the cyclone trajectory (Fig. 3) and performed a detailed diagnosis of the vortex structure, showing that the cyclone had the typical features of a tropical storm, such as spiral cloud shape, clearly defined eye, sharp pressure gradients around the eye, strong surface wind and warm core. The diameter of the eye of the vortex was evaluated to be about $60-70 \mathrm{~km}$, using satellite images, surface and radar observations.

The passage of the vortex over the Salentine Peninsula produced a wind gust exceeding $78 \mathrm{kt}$ in response to very large pressure gradient (approximately $10 \mathrm{hPa} / 20 \mathrm{~km}$ ) and a dramatic fall of the surface pressure: in less than four hours, several surface stations recorded a sharp decrease of the mean sea level pressure, reaching a minimum value of $986 \mathrm{hPa}$ between 09:00 and 10:00 UTC, and a quick return to pre-cyclone values (around $1005 \mathrm{hPa}$ ). Radar reflectivity maps (Fig. 4) clearly showed the passage of a cloud-free

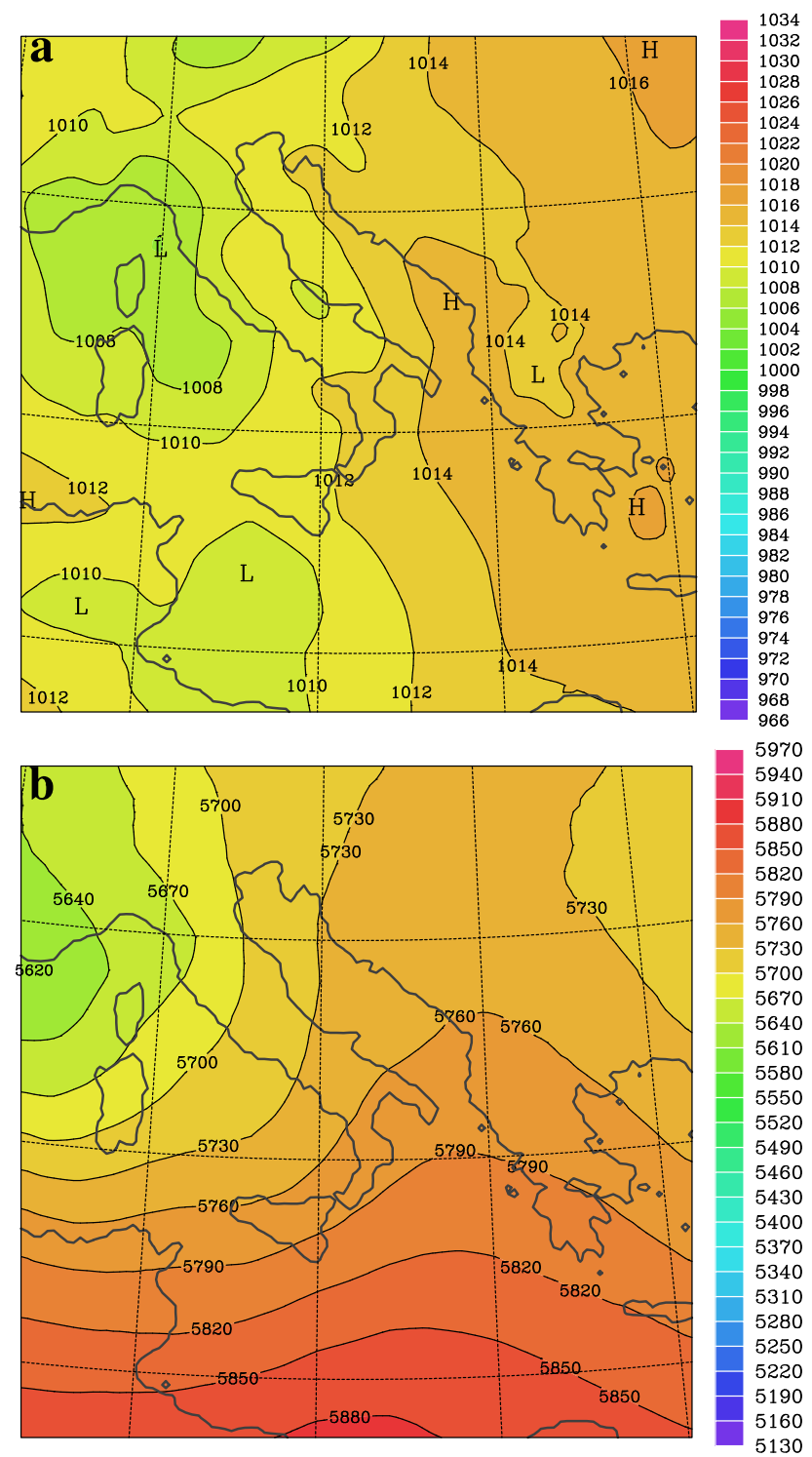

Fig. 2. GFS-NCEP model analysis at 12:00 UTC, 25 September 2006, interpolated on the BOLAM grid. (a) Mean sea-level pressure (contour interval $2 \mathrm{hPa}$ ) and (b) geopotential height at $500 \mathrm{hPa}$ (c.i. $30 \mathrm{dam})$. 


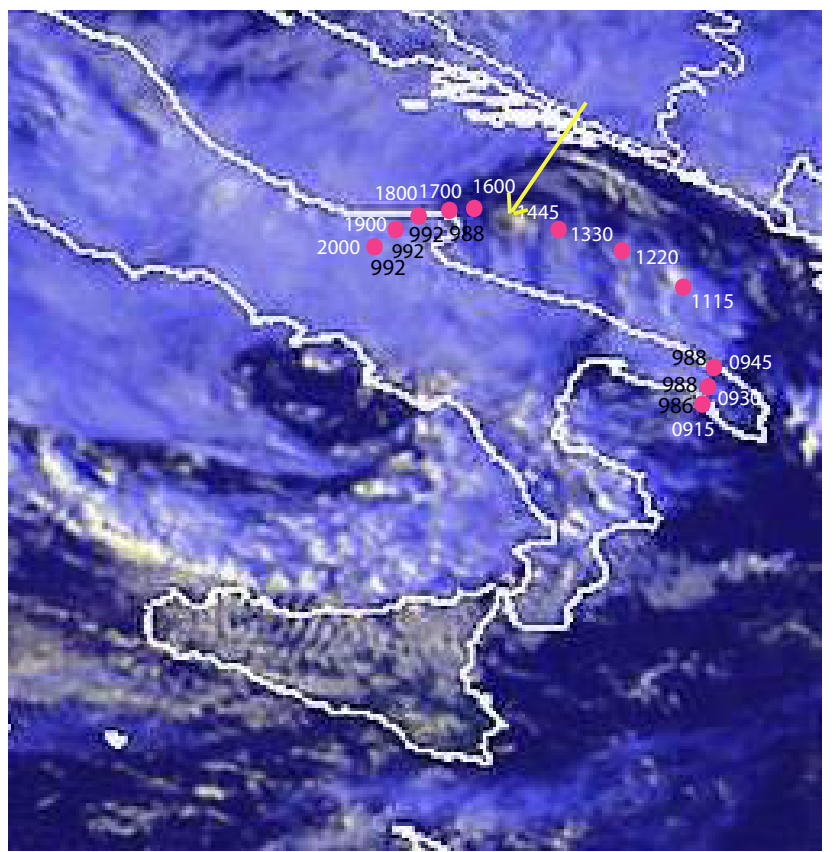

Fig. 3. Multispectral Meteosat Second Generation image at 14:45 UTC, 26 September 2006 (font: CESI http:/meteo.cesi.it; copyright EUMETSAT). The position of the TLC over the Adriatic Sea is indicated by the arrow. The cyclonic large-scale circulation over the Tyrrhenian Sea is also clearly evident. The location of the cyclone is also shown between 09:00 and 20:00 UTC, 26 September 2006 as reconstructed from the observational data. Numbers along the trajectory indicate the time (UTC, in white) and the minimum mean sea level value ( $\mathrm{hPa}$, in black).

eye through the region. Later in the day (Fig. 3), the vortex moved over the Adriatic Sea where, driven by the largescale cyclonic circulation centred over the southern Tyrrhenian Sea, it followed an arc-shape trajectory maintaining the characteristics and the intensity of a TLC. Indeed, when it reached the Italian coast again at around 17:00 UTC, the low was still very deep with a mean sea level pressure value of $988 \mathrm{hPa}$ recorded at the Gargano promontory (Figs. 1b and 3). After this second landfall, the vortex weakened rapidly while moving inland and finally merged with the primary low-pressure system.

\subsection{Control forecast}

Among all the operational forecasts performed with BOLAM and MOLOCH covering the analysed period, the one initialized at 12:00 UTC, 25 September 2006 showed a remarkably good agreement with the subsequent observed evolution of the TLC. This forecast is therefore selected and described in the following in order to complement the previous analysis and to examine the characteristics and the structure of the TLC. Figure 5a shows the mesoscale vortex at 09:00 UTC, 26 September, just after the rapid intensification $(14 \mathrm{hPa}$ in

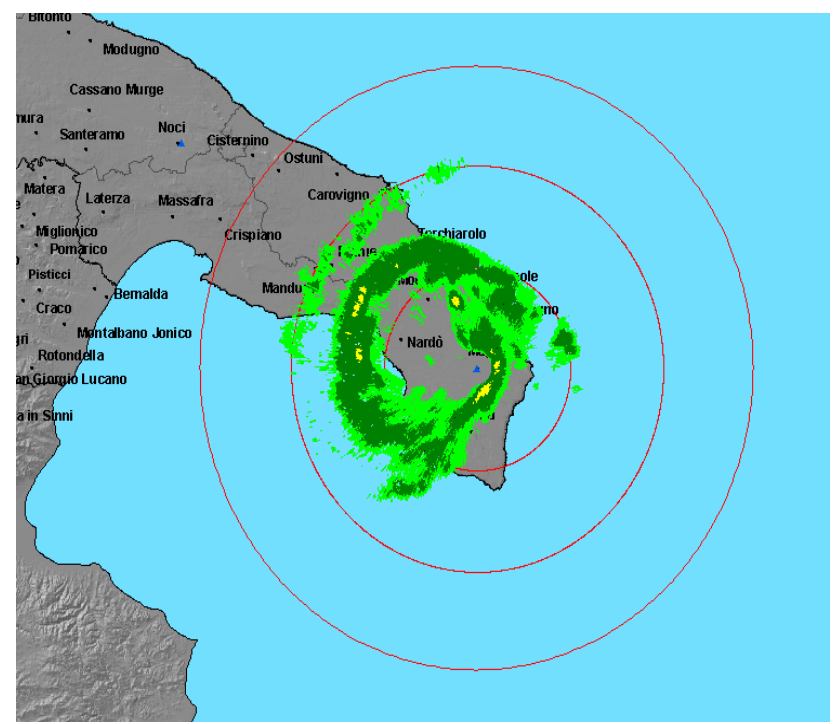

Fig. 4. Reflectivity map (elevation 2.75") in $\mathrm{dBz}$ from the radar located in Maglie (courtesy SMA S.p.A.) on 26 September 2006 at 11:03 UTC.

$9 \mathrm{~h})$ and the landfall, as forecast by BOLAM. The intensity of the cyclone (the pressure minimum is about $988 \mathrm{hPa}$ ) and location compare well with the observations (Figs. 6a and 3). Later, driven by the mid-tropospheric cyclonic circulation imposed by the low-pressure system over the Tyrrhenian Sea (Fig. 5b), the forecast cyclone moves over the Adriatic Sea where it further intensifies (Fig. 6a and b). The lack of pressure data over the sea prevents a direct comparison with the observations during this eventual deepening phase, except for satellite and radar images (Fig. 3) which clearly display intense convective activity organized around a cloud-free centre, an indication of a still vigorous cyclonic circulation. Finally, BOLAM forecasts the second landfall over the Gargano promontory at the correct time (around 17:00 UTC) but with a slight overestimation of the vortex intensity $(984 \mathrm{hPa})$. The zonal cross section of potential temperature and meridional wind in Fig. 7, taken across the deep surface low over the Adriatic Sea, reveals some of the typical features of a TLC (Rasmussen and Zick, 1987; Reale and Atlas, 2001): limited horizontal extent of the mesoscale cyclone (around $100 \mathrm{~km}$ ) that displays an axi-symmetric shape, a warm core and a windless column of air centred over the pressure minimum, extending up to the tropopause, surrounded by a region of strong horizontal wind shear at lower levels and almost no vertical wind shear. In correspondence with the cyclone warm core there is also a distinct maximum of potential vorticity (not shown) at lower levels.

The results of high-resolution MOLOCH forecasts nested in BOLAM may considerably differ from those of the driving model. Indeed, although the larger-scales motions allowed by the MOLOCH domain are constrained to follow BOLAM 

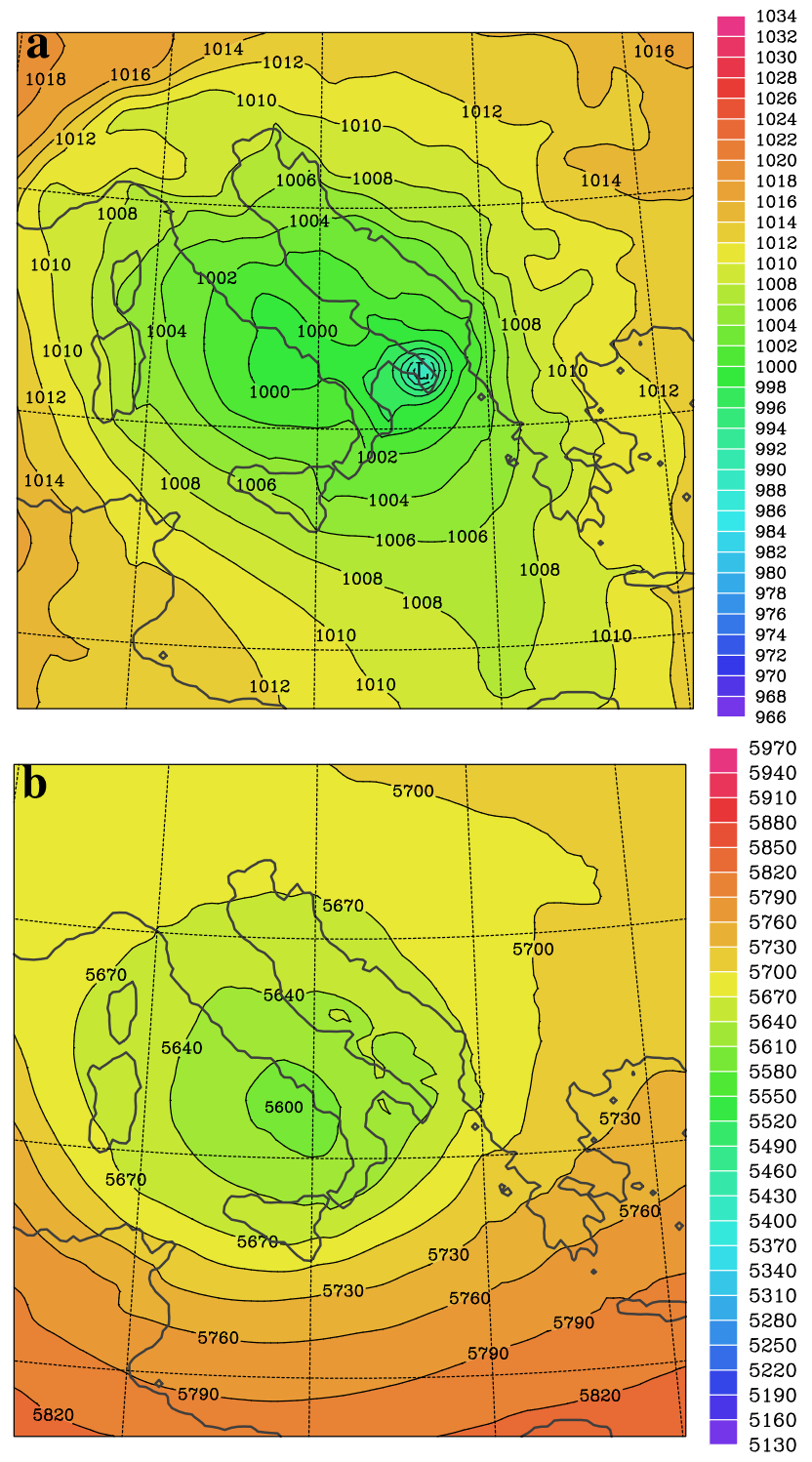

Fig. 5. BOLAM control run: (a) mean sea-level pressure (c.i. $2 \mathrm{hPa}$ ) and (b) geopotential height at $500 \mathrm{hPa}$ (c.i. 30 dam) at 09:00 UTC, 26 September 2006, after a $21 \mathrm{~h}$ forecast.

evolution, the smaller-scales motions may vary considerably as a consequence of the higher resolution, the nonhydrostatic effects and the explicit treatment of deep moist convection. In this respect, the MOLOCH forecasts are directly comparable with the WRF inner-grid simulations.

In the high-resolution forecast, provided by MOLOCH and initialized at 00:00 UTC, 26 September, the deepening of the cyclone over the Ionian Sea is strictly connected with the development of intense convective precipitation close to the eastern coast of Calabria. Miglietta et al. (2008) ascribed this rainfall to the strong uplift due to the interaction of the south-easterly low-level flow, preceding the cyclone, with the steep orography of Calabria. As a consequence of an im-

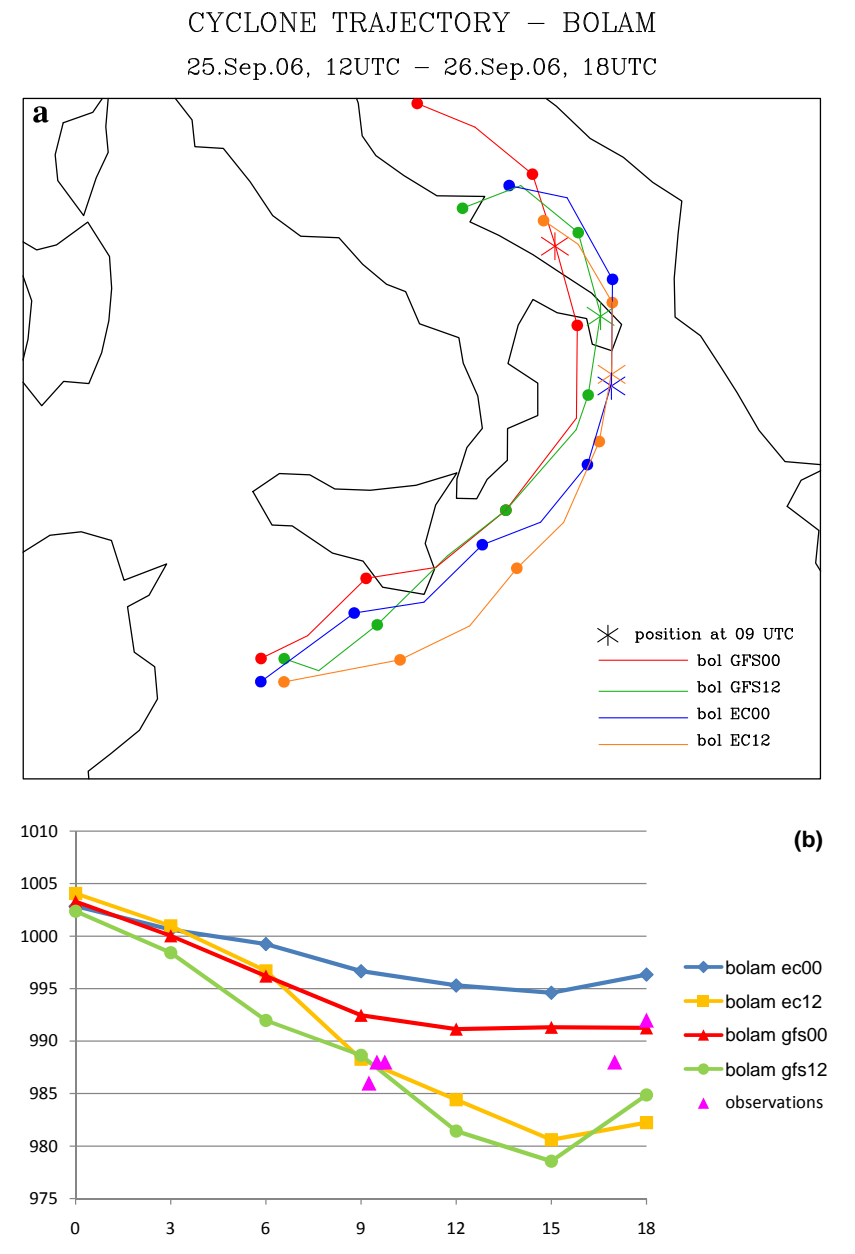

Fig. 6. BOLAM forecast results: (a) track of the cyclone between 12:00 UTC, 25 September and 18:00 UTC, 26 September 2006 (filled points denote the location of the vortex every $6 \mathrm{~h}$, asterisks indicate the position forecast at 09:00 UTC, 26 September); (b) intensity of the cyclone pressure minimum (hPa) between 00:00 UTC and 18:00 UTC, 26 September. Every line corresponds to a BOLAM simulation nested into a different forecast of the driving global model identified by the label (see also text). Magenta triangles indicate observed values of mean sea-level pressure at surface stations at the passage of the vortex (but not necessarily co-located with the vortex centre).

pressive pressure drop of $10 \mathrm{hPa}$ in $6 \mathrm{~h}$ the vortex reaches its mature phase and crosses the Salentine Peninsula between 08:00 and 10:00 UTC, characterized by a simulated minimum pressure value of $985 \mathrm{hPa}$ (Fig. 8) and strong low level winds (the simulated maximum wind speed at 09:00 UTC is $26 \mathrm{~m} / \mathrm{s}$ ). Both the forecast trajectory and cyclone intensity (Fig. 9a and b) agree very well with the observations. After the rapid transit over land, the simulated cyclone further deepens over the Adriatic Sea, attaining the maximum intensity at around 12:00 UTC (977 hPa). Later it begins to fill and, at the time of the second landfall (around 18:00 UTC, a bit later than observed), the minimum pressure is $984 \mathrm{hPa}$. 


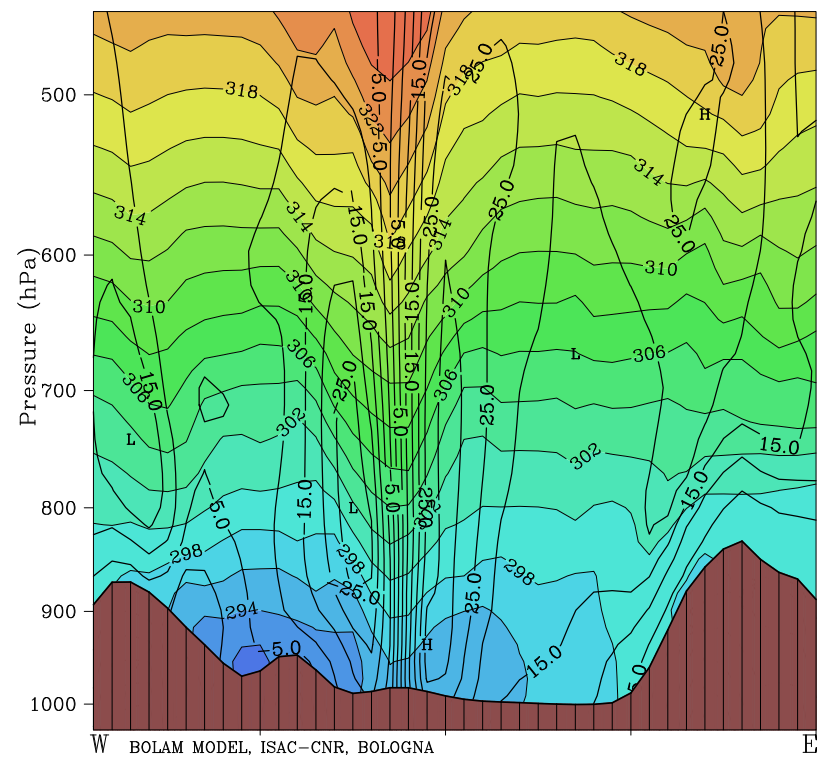

Fig. 7. BOLAM control run after $26 \mathrm{~h}$, valid at 14:00 UTC, 26 September 2006: zonal cross section of potential temperature (shading and thin lines, contour interval $2 \mathrm{~K}$ ) and meridional wind (thick lines, c.i. $5 \mathrm{~m} / \mathrm{s}$ ) taken across the surface low.
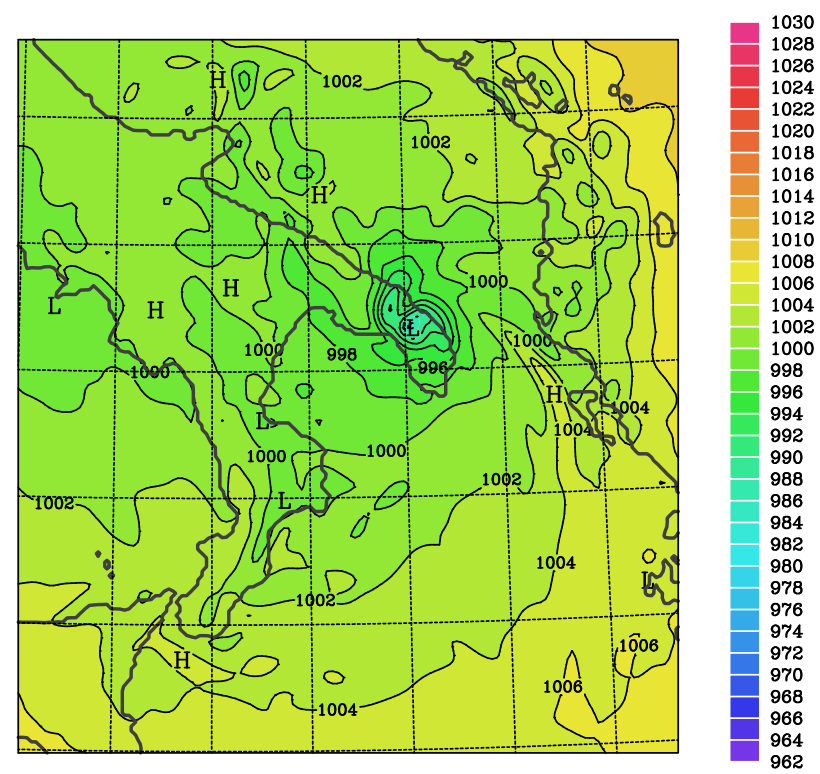

Fig. 8. MOLOCH control run: mean sea-level pressure (c.i. $2 \mathrm{hPa}$ ) at 09:00 UTC, 26 September 2006, after a $9 \mathrm{~h}$ forecast.

As with BOLAM, also MOLOCH produces a slight overestimation of the cyclone intensity at the second landfall. This fact suggests that both models probably tend to excessively deepen the vortex over the Adriatic Sea.

Although the high-resolution forecasts (both MOLOCH and WRF) provide a suitable reference description of the cyclone dynamics and structure, the prediction of the rain-
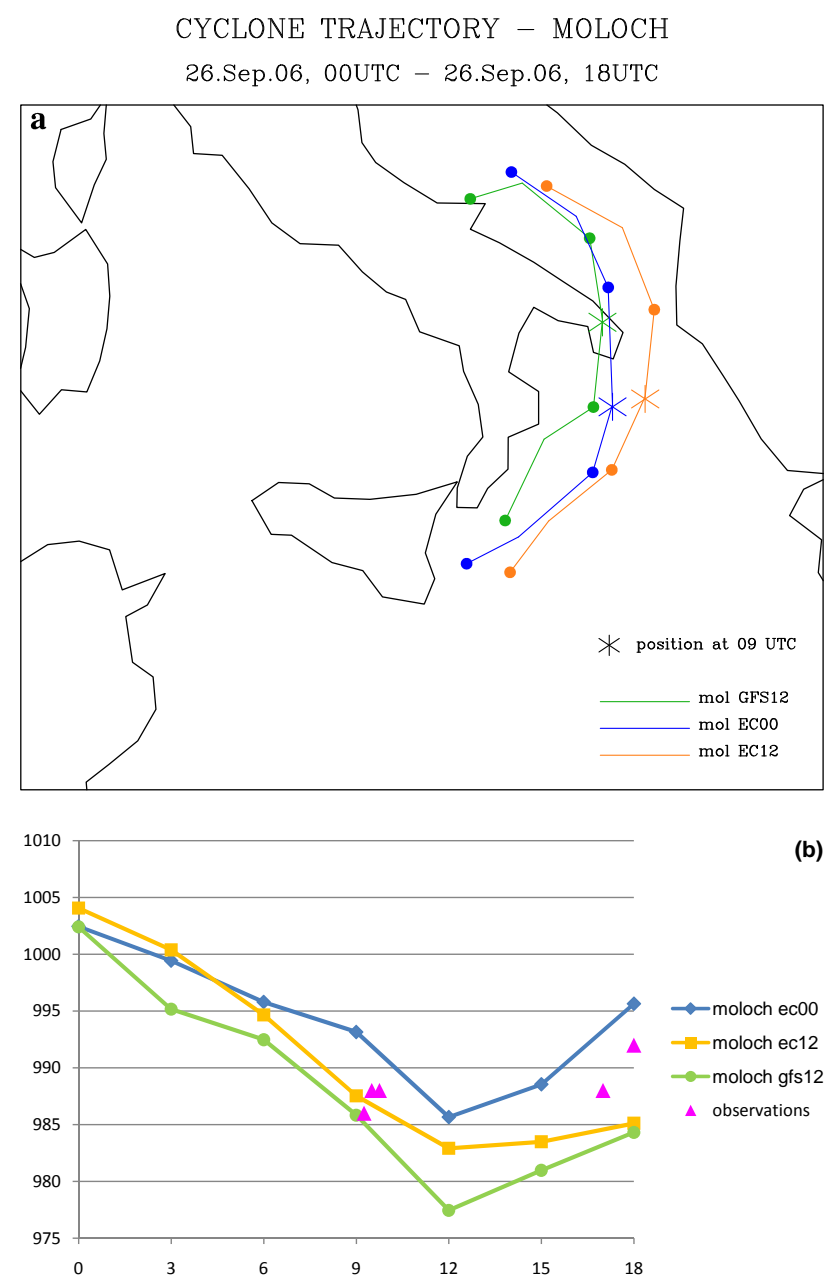

Fig. 9. As in Fig. 6, but for MOLOCH between 00:00 UTC and 18:00 UTC, 26 September 2006. In (a) the track of the cyclone is plotted every $6 \mathrm{~h}$ (asterisks indicate the forecast position at 09:00 UTC). The run driven by GFS00 is not included as it misses the formation of the vortex.

fall associated with the passage of the vortex over Salentine Peninsula seems to be unsatisfactory. The raingauge (the distribution of the stations in the region is shown in Moscatello et al., 2008b) recordings between 06:00 and 12:00 UTC, 26 September (Fig. 10a) display two intense precipitation areas (around $50-60 \mathrm{~mm} / 6 \mathrm{~h}$ ) over the peninsula and another one over the Gargano promontory. Both MOLOCH and WRF control simulations (Fig. 10b and c) tend to overestimate the amount of rainfall, producing maxima larger than $100 \mathrm{~mm} / 6 \mathrm{~h}$. Over the Salentine Peninsula, MOLOCH forecasts two maxima but displaced by about 30-40 km NNE with respect to the observations, while WRF results better capture the mode and evolution of the rain band. Over the Gargano promontory the forecasts are better, although they suffer from a remarkable overestimation. 

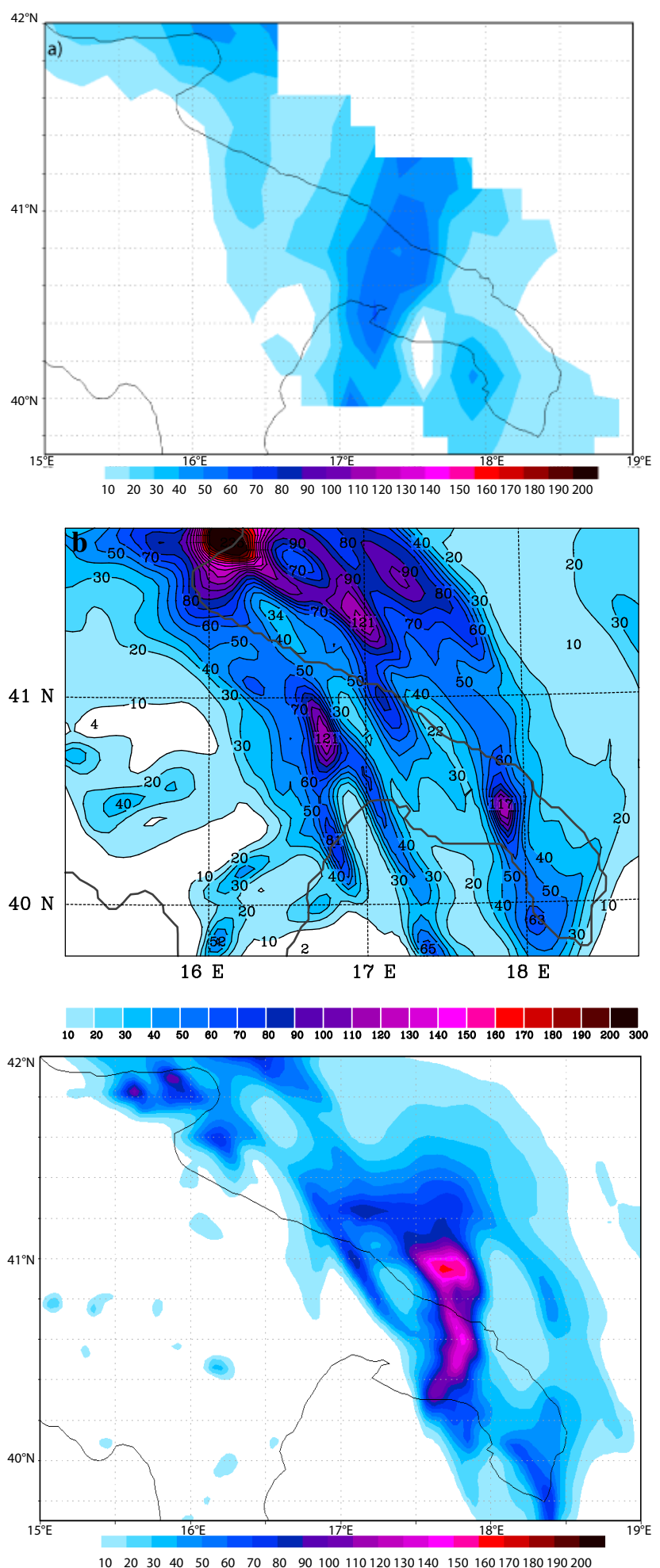

Fig. 10. 6h-accumulated rainfall (shading and contour interval $10 \mathrm{~mm}$ ) at 12:00 UTC, 26 September 2006. (a) Observations, (b) $12 \mathrm{~h} \mathrm{MOLOCH}$ forecast and (c) $24 \mathrm{~h}$ WRF forecast.
CYCLONE TRAJECTORY - GLOBAL MODEL

25.Sep.06, 12UTC - 26.Sep.06, 18UTC
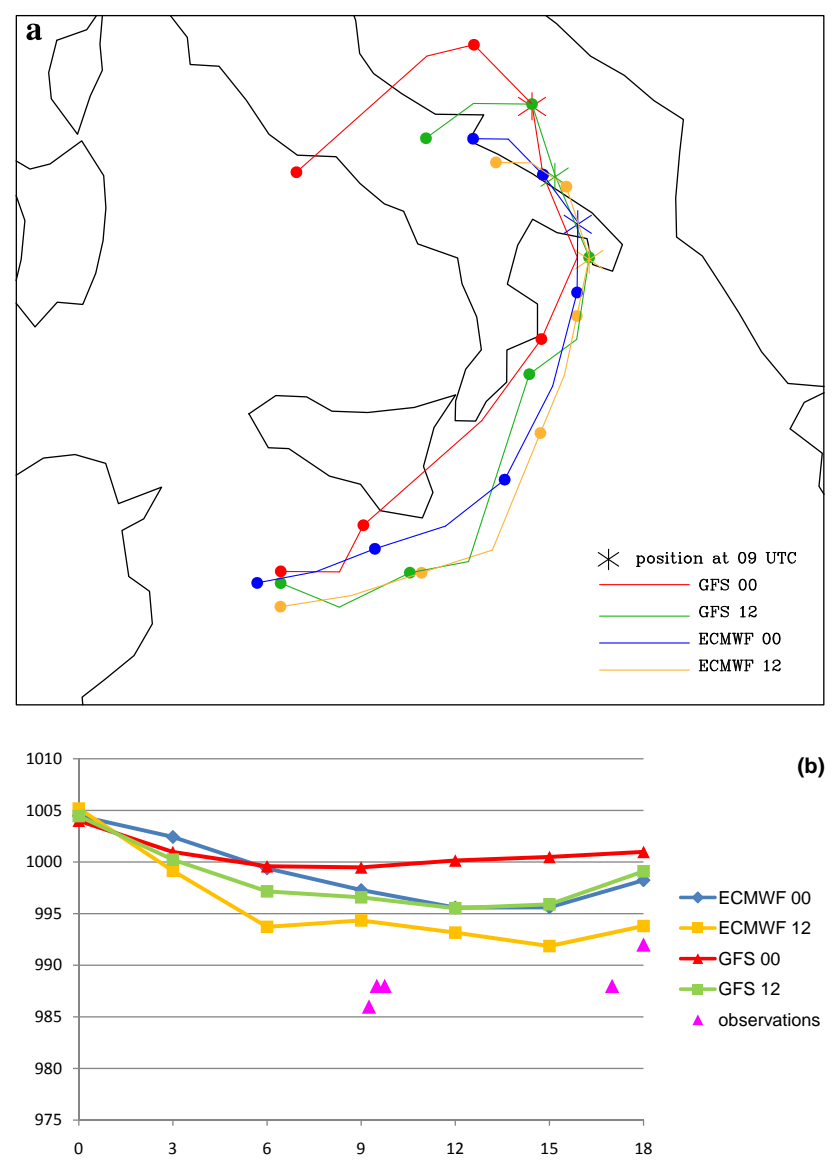

Fig. 11. As in Fig. 6, but for global models (GFS-NCEP and ECMWF).

\section{Predictability analysis}

Several simulations in a real-time configuration were performed with both forecasting chains (BOLAM-MOLOCH and WRF) in order to evaluate the predictability of the event as a function of model and initial conditions. Two starting times were selected, 00:00 and 12:00 UTC, 25 September 2006. Moreover, in addition to the GFS-NCEP analysis/forecasts employed for the operational activity, the ECMWF model analysis/forecasts (at three hour intervals) were used as initial and boundary conditions for the coarseresolution simulations in this set of experiments, allowing for a multi-model, multi-analysis ensemble, although with a limited number of members.

\subsection{Global models}

Before analysing in detail the results of the limited-areamodel simulations, a brief overview of the parent globalmodel forecasts is provided in the following (Fig. 11). The 
CYCLONE TRAJECTORY

26.Sep.06, 00UTC - 26.Sep.06, 18UTC WRF model (inner grid)
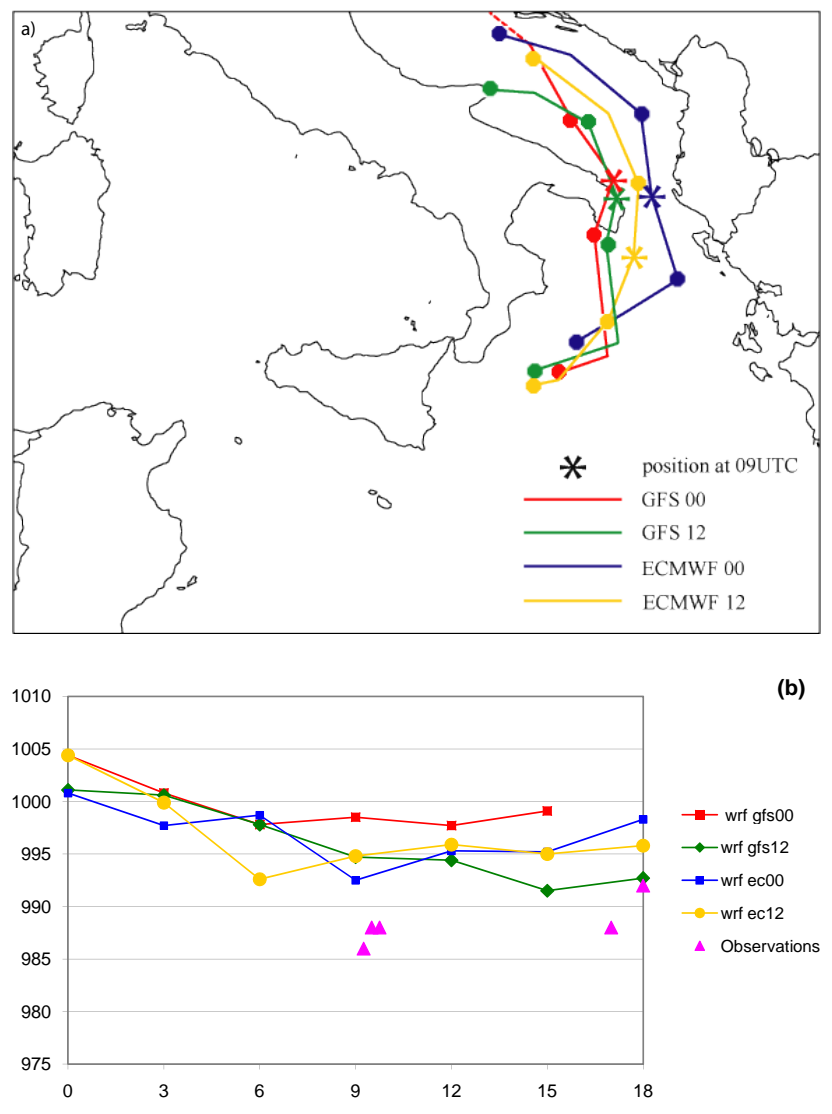

Fig. 12. As in Fig. 6, but for WRF inner grid, between 00:00 UTC and 18:00 UTC, 26 September 2006.

GFS forecast from 00:00 UTC, 25 September (GFS00), is the least successful, since it produces only a shallow minimum $(999 \mathrm{hPa})$ over the Ionian Sea which reaches the Salentine Peninsula too early (between 00:00 and 03:00 UTC, 26 September) and then moves over the Adriatic Sea, quickly dissipating at around 15:00 UTC far from the Italian coast. The GFS simulation from 12:00 UTC, 25 September (GFS12), displays a better agreement with the observations: although the cyclone landfall is forecast a few hours earlier (at 06:00 UTC), the vortex has a well defined structure and an intensity of $997 \mathrm{hPa}$; however, the second landfall occurs too early (at 15:00 UTC). A cyclone with similar intensity to that of GFS12 is also predicted by the ECMWF model initialized at 00:00 UTC, 25 September (EC00), but in contrast with the GFS12 forecast, the timing is correct. After having deepened over the Ionian Sea, the EC00 vortex is predicted over the Apulia region at 09:00 UTC and the Gargano promontory at 17:00 UTC. Finally, the best global-model forecast is provided by ECMWF starting at 12:00 UTC, 25 September (EC12): the cyclone over the Ionian Sea undergoes a quick intensification in the early morning of 26 September, acquir- ing the characteristics of an intense TLC; it then crosses the Salentine Peninsula at 09:00 UTC with a minimum of 994 hPa. However, its subsequent transit over the Adriatic Sea is not in good agreement with the observed trajectory, since the EC12 forecast cyclone moves along the coastline, never reaching the Gargano promontory.

\subsection{Limited area models}

The results in terms of forecast trajectory and cyclone intensity concerning the limited area models are presented in Fig. 6a and b for BOLAM, Fig. 9a and b for MOLOCH and Fig. 12a and $b$ for WRF.

As stressed in the previous section, the BOLAM run nested in the GFS12 provides the best forecast in terms of minimum pressure values and locations. It has therefore been selected as the control simulation. The timing of the two landfalls agrees very well with the observations, and the intensity of the vortex during its transit over the Apulia region is close to that observed (Fig. 6). Also the simulation driven by $\mathrm{EC} 12$ properly forecasts the vortex intensity, but the cyclone seems to move too slowly along its trajectory, which is shifted eastward compared with the observations. Moreover, the forecast vortex never reaches the Gargano promontory while the observed vortex reached the area by the evening of 26 September. These characteristics are maintained in the respective MOLOCH high-resolution simulations (Fig. 9): the control run displays the best agreement with the observed trajectory, while the run driven by EC12 produces a cyclone that moves around Italian peninsula, never crossing it. In general, the two latter simulations seem to excessively deepen the cyclone over the Adriatic Sea, since the mean sea-levelpressure minimum predicted by the evening of 26 September over the Gargano promontory is lower than observed. However, a direct comparison with the observations is not possible because of the lack of pressure data over the sea. The other two BOLAM runs, nested in GFS00 and EC00, produce weaker cyclones. In the first case, the vortex moves too fast and too much to the north, while in the other forecast the cyclone moves slightly slower than observed. The latter characteristic is present also in the respective MOLOCH forecast. Conversely, MOLOCH does not produce any mesoscale vortex over the region when it is nested in the BOLAM driven by GFS00 forecast. This is the only simulation that completely fails in forecasting the TLC development. However, additional experiments performed with larger MOLOCH integration domains remarkably reduce this forecast error providing hints of deep cyclogenesis.

The high-resolution WRF simulations produce in general a weaker cyclone in terms of minimum mean sea-levelpressure values compared with BOLAM and MOLOCH, although a sub-synoptic scale vortex is always generated. As seen for BOLAM and MOLOCH, the forecast driven by GFS12 presents the best agreement with the observations in terms of predicted trajectory. The cyclone seems too weak at 
the time of its first landfall ( $994 \mathrm{hPa}$ ) which is forecasted only slightly in advance, while in the evening it compares well with the observations. The timing of the first passage over land is correctly forecasted also by the run driven by GFS 00 . However, the cyclone appears very weak and moves too far to the north over the Adriatic Sea. When the ECMWF analyses/forecasts are used, WRF forecasts a cyclone of moderate intensity (around $992 \mathrm{hPa}$ ) that moves around the Apulia region without passing over land.

In general, the above experiments show that the trajectory of the cyclone is mainly dependent on the initial/boundary conditions employed (ECMWF or GFS). On the other hand, the depth of the cyclone is mainly dependent on the choice of the model, as its absolute minimum is generally much deeper in the case of BOLAM and MOLOCH models than for WRF. Different intensity of the vortex forecast by the three models can be ascribed to different intensities of the surface fluxes as shown by Miglietta et al. (2008). This indicates that the trajectory depends mainly on the larger-scale-flow characteristics, while the vortex growth is particularly sensitive to local dynamics. A clear forecast improvement is obtained by embedding limited area models into global models, because the low resolution of the latter does not allow for a proper representation of the mesoscale features associated with the vortex.

The mean trajectory for the eleven simulations performed with the LAMs (excluding the MOLOCH simulation that does not develop any vortex) is shown in Fig. 13. The mean trajectory appears quite close to the observed path, as it is shifted just about $20 \mathrm{~km}$ to the east and similarly turns cyclonically. The spread among the individual simulations is however quite large (not shown) and the ensemble spans mainly the area to the east of the mean track. However, the ensemble of the six out of eleven "best" trajectories (in the sense that minimize the sum of the distances with respect to the mean trajectory over the four selected time steps between 09:00 and 18:00 UTC) spans the region represented with the shaded area. The fact that this area is quite narrow and includes most of the observed track represents an indication of the skill and consistency of these simulations. There is no evidence of a definite increase of the spread of the trajectories during the analysed period, as also confirmed by computing the error in track as a function of time (not shown). This is probably a consequence of the short forecast interval that can be evaluated, compared to the whole TLC life cycle, since observational data concerning the trajectory are available for comparison only between 09:00 and 18:00 UTC.

Finally, comparing the WRF model results with the control run shown in Moscatello et al. (2008a), it is clear that using a larger domain and starting the simulation earlier may significantly improve the model predictions, although this setup is presently too expensive in terms of computational cost for the RISKMED real-time application.

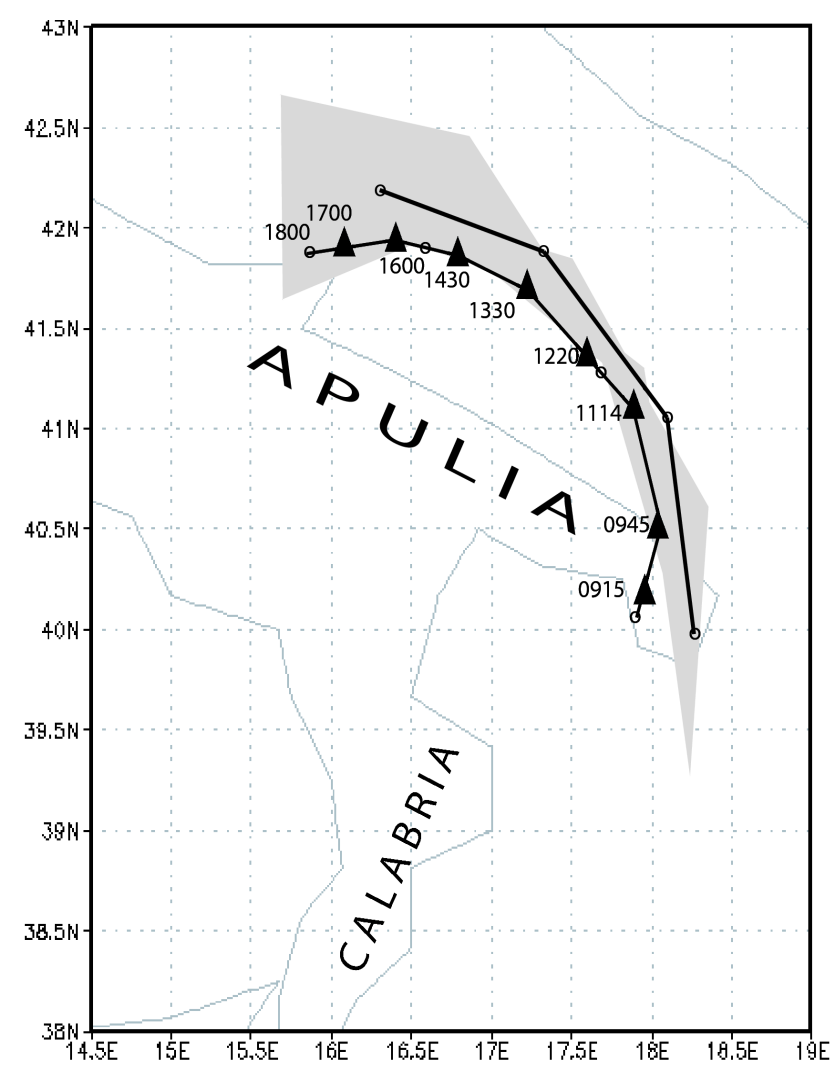

Fig. 13. Mean trajectory (solid line with open circles at $3 \mathrm{~h}$ interval) for the eleven simulations performed with the LAMs (excluding the MOLOCH simulation that does not develop any vortex) and ensemble of the six out of eleven "best" trajectories (see text) between 09:00 and 18:00 UTC, 26 September 2006. Observed trajectory (solid line with triangles) is also plotted. Open circles are plotted also on the observed trajectory at $3 \mathrm{~h}$ interval for comparison with the mean trajectory.

\section{Role of surface fluxes and latent heat release}

The analysis of the vortex presented in Sect. 2 allows for the identification of different phases of the TLC life cycle: the orographic origin of the disturbance, a first intensification during its passage over the Strait of Sicily, the mature phase over the Ionian Sea and the transit over the Salentine Peninsula, and finally the further movement over the Adriatic Sea till the second landfall and decay. In the following, by means of sensitivity experiments, we will focus our attention on the contribution of surface (sensible and latent) heat fluxes and latent-heat release, due to convective activity, to the development of the cyclone along its trajectory, while for the analysis of the mechanisms responsible of the origin of the disturbance see Moscatello et al. (2008a).

In order to assess the role of surface fluxes, several BOLAM simulations were performed using the same configuration as the control run, but switching off the surface fluxes at different times, namely $0,6,12$ and $22 \mathrm{~h}$ after the 


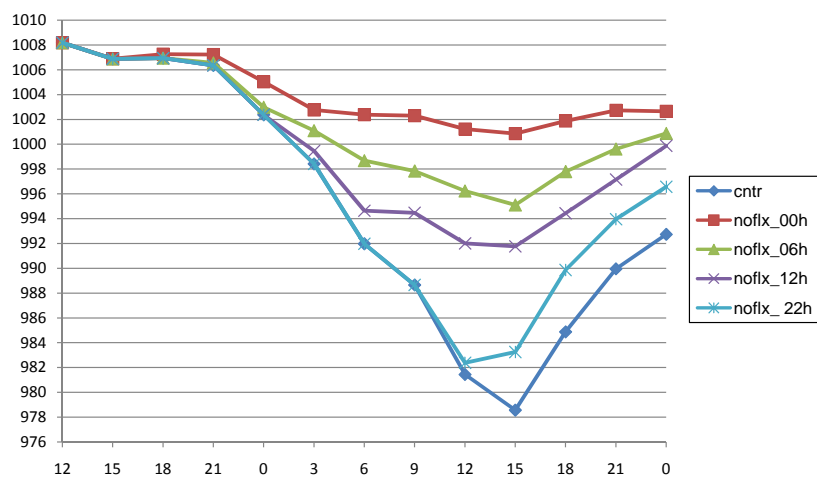

Fig. 14. Mean sea-level pressure minimum (hPa) for the BOLAM sensitivity experiments from 12:00 UTC, 25 September, to 00:00 UTC, 27 September 2006.

initialization. Differences with respect to the control run can be attributed only to the contribution of surface fluxes in the different phases of the vortex trajectory. Results are summarized in Fig. 14. The effect of turning off the surface fluxes from the beginning of the simulations (experiment noflx_00h), that is at 12:00 UTC, 25 September, is dramatic, since the orographic depression quickly disappears south of Sicily and no sub-synoptic scale vortex is formed (compare Fig. 5a with Fig. 15). Leaving the surface fluxes active for the first six hours (exp. noflx_06h), until 18:00 UTC, implies that their contribution is present during the transit of the cyclone over the Strait of Sicily. In this case the cyclone intensifies as in the control run until 00:00 UTC, 26 September, but the pressure decreases at a slower rate in the following hours. A small-scale vortex develops (not shown) and reaches Apulia, but with a remarkably lower intensity than in the control experiment. In a third experiment (noflx_12h) the surface fluxes are turned off after $12 \mathrm{~h}$ (at 00:00 UTC, 26 September), after the depression has passed Sicily and reached the coast of Calabria. In this case a TLC develops even though, at the time of its landfall at 09:00 UTC (not shown), its intensity is around $994 \mathrm{hPa}$, which is in contrast with the value of $988 \mathrm{hPa}$ of the control run. This set of experiments highlights the critical importance of surface fluxes in the initial phase of development of the cyclone as it moves south of Sicily. These results support the conclusion of Moscatello et al. (2008a), in which sensitivity experiments performed using WRF showed that the surface fluxes, by increasing moisture in the boundary layer, were fundamental for the destabilization of the environment, needed to trigger convective activity and consequently intensify and contract the horizontal scale of the vortex. Although surface fluxes do not attain high values during this phase, especially in comparison with the subsequent mature stage of the vortex, they turn out to be essential for the subsequent development of the vortex.

The subsequent phase is characterized by a rapid intensification while the vortex moves along the coast of Calabria

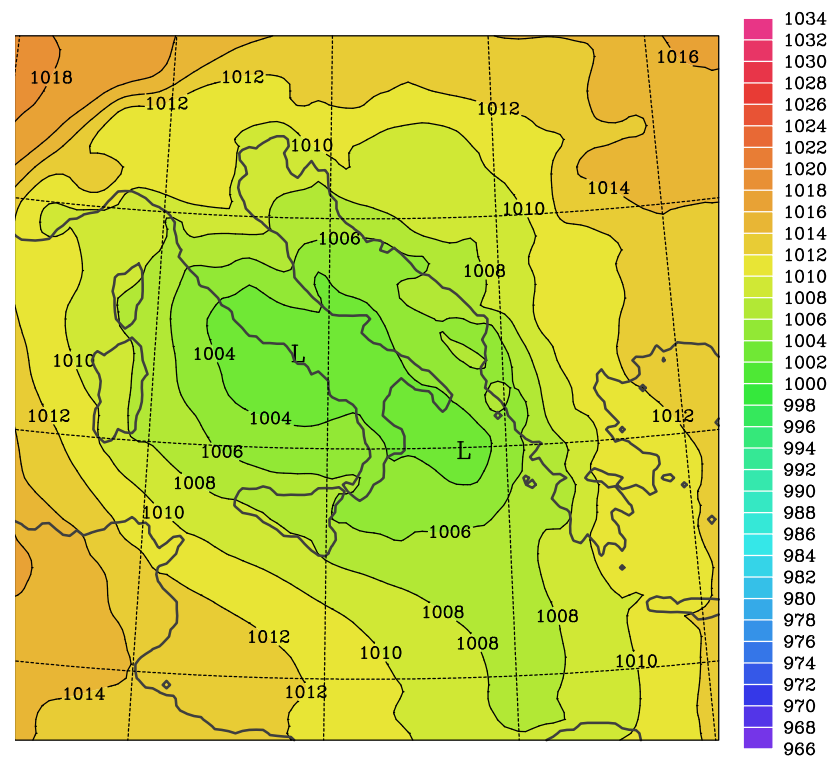

Fig. 15. BOLAM sensitivity experiments (see text): mean sea-level pressure (c.i. $2 \mathrm{hPa}$ ) at 09:00 UTC, 26 September 2006. Surface fluxes are turned off.

and over the Ionian Sea during the first hours of 26 September. For this period, the MOLOCH forecasts are available and it is therefore possible to investigate the role of latent-heat release associated with convective-precipitation processes, since MOLOCH explicitly resolves deep convection without any parameterization scheme. Two MOLOCH experiments were performed, with the same set-up as in the control simulations, but turning off alternatively the surface fluxes (exp. mol_noflx_00h) or the latent-heat release (exp. mol_nolh_00h) from the beginning of the simulation (00:00 UTC, 26 September). Figure 16 clearly shows that the main process responsible for the rapid deepening of the cyclone is the latent-heat release associated with the convection. Without this contribution, the cyclone does not intensify and only a shallow depression forms (Fig. 17). On the other hand, the suppression of the surface fluxes alone does not prevent the formation of a small scale deep vortex that reaches the Salentine Peninsula (not shown), even though it is weaker than in the MOLOCH control run. Similar sensitivity experiments performed with WRF (Moscatello et al., 2008a) reached the same conclusions. During this phase surface fluxes increase as a consequence of stronger low-level wind around the vortex, but they are not critical and play only a marginal role in terms of cyclone deepening. The release of latent heat due to the development and organization of strong convective activity, associated with intense precipitation close to Calabrian coast, is the key factor in determining the rapid deepening of the small-scale vortex. Similar conclusions were reached in a previous study (Lagouvardos et al., 1999) in which the authors evaluated the importance of the surface fluxes (sensible and latent heat) during the 


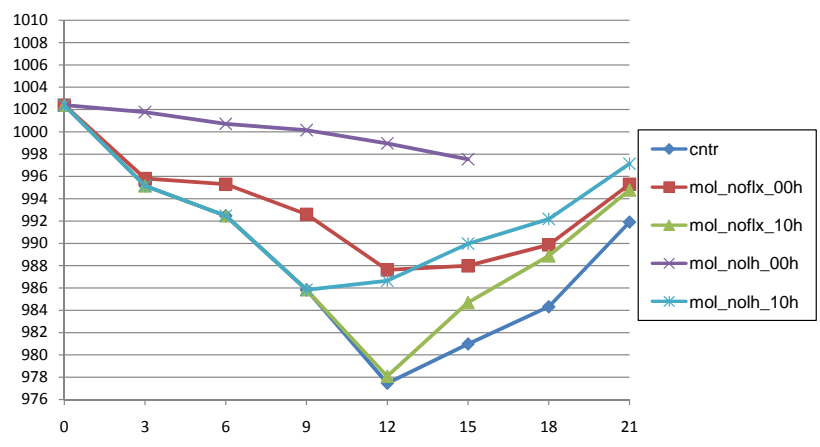

Fig. 16. Mean sea-level pressure minimum (hPa) for the MOLOCH sensitivity experiments from 00:00 UTC, to 21:00 UTC, 26 September 2006.

formation of the TLC and the critical impact of the latent heat release due to the convection during the mature stage.

Therefore, both surface fluxes and latent-heat release are necessary for the transition of the large-scale depression to a small-scale hurricane-like vortex (McTaggart-Cowan et al., 2007), although each effect contributes during different phases.

The cyclone finally moves over the Adriatic Sea maintaining (and even deepening) its impressive intensity and the structure of a TLC. A BOLAM simulation (exp. noflx_22h) similar to the control run, but with surface fluxes turned off since 10:00 UTC, 26 September (after cyclone landfall), emphasizes the important impact of heat and moisture exchanges over the Adriatic Sea on the cyclone strength (Fig. 14). This result is supported by a similar MOLOCH simulation (exp. mol_noflx_10), driven by the BOLAM control run, in which surface fluxes are set to zero after 10:00 UTC, 26 September (Fig. 16). If the latent-heat release, instead of surface fluxes, is switched off in the MOLOCH simulation after 10:00 UTC (exp. mol_nolh_10h), the resulting cyclone is even weaker. Therefore, both surface fluxes and latent-heat release are important in maintaining the intensity of the TLC over the Adriatic Sea, although the latter factor seems to be the most important. Again the WRF sensitivity experiments (Moscatello et al., 2008) agree with this conclusion that supports the hypothesis of a physical mechanism similar to that responsible of the intensification of the hurricanes (WISHE theory; Rotunno and Emanuel, 1987). During this phase the system clearly resembles a small-scale tropical cyclone and moves in a barotropic environment fed by air-sea interaction processes. A more detailed analysis of the horizontal structure of the surface fluxes and the contribution of moisture (latent heat) fluxes with respect to sensible heat fluxes is presented in Miglietta et al. (2008).

It is worth noting that in this event, the upper-level potential vorticity (PV) was not relevant for the development of the TLC, at variance with other episodes (Reale and Atlas, 2001; Homar et al., 2003). Although at the end of the mature

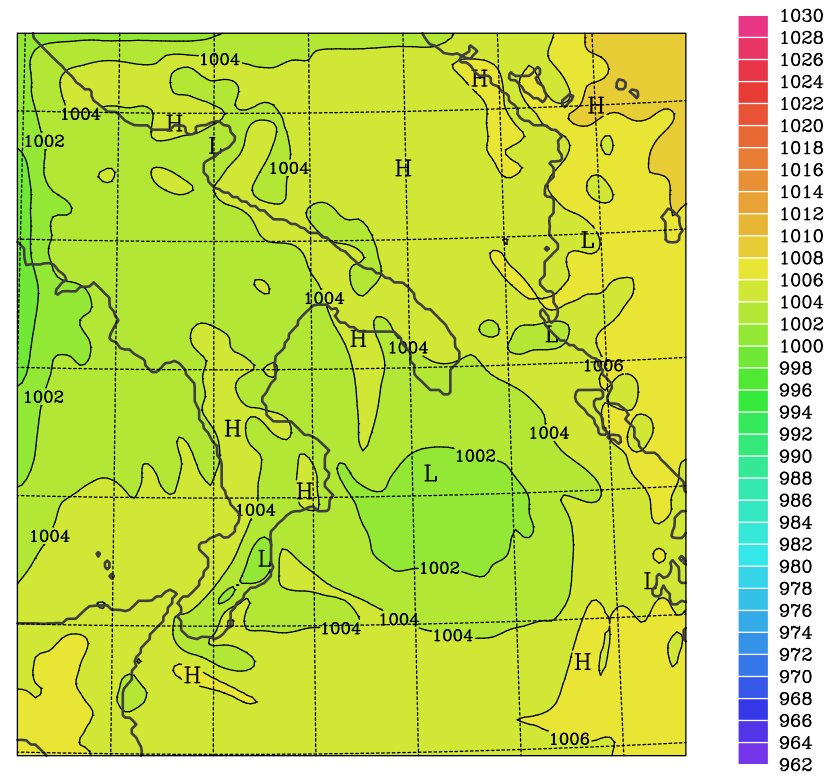

Fig. 17. Mean sea-level pressure (c.i. $2 \mathrm{hPa}$ ) at 09:00 UTC, 26 September 2006 obtained by MOLOCH sensitivity runs in which the latent-heat release is turned off from the beginning of the simulation (00:00 UTC, 26 September).

stage an upper-level PV anomaly moves close to the area affected by the vortex, additional experiments did not provide any evidence of a relationship between the low level vortex intensification and the upper level disturbance. In contrast, the vortex was associated with a distinct low-level PV maximum that appeared in simulations after it moved over the Ionian Sea and intensified with the increase of the low-level circulation.

\section{Conclusions}

The present paper focuses on the application of a real-time modelling chain to the prediction of a severe event that occurred on 26 September 2006 in which an intense mesoscale vortex developed over the Ionian Sea affecting the extreme south-eastern part of Italy, producing strong wind damage in the region. Both model simulations and observational analysis agree in identifying the typical characteristics of a TLC, such as eye-like features, strong wind, warm core, high vorticity values and no vertical tilt.

The predictability of this event has been tested by using a multi-model, multi-analysis approach. In particular, different limited area models (BOLAM, MOLOCH and WRF) were forced with initial and boundary conditions provided by the different runs (initial time: 25 September 2006, 00:00 and 12:00 UTC) of different global models (GFS, ECMWF). By comparing them with the global-model forecasts, we find that the limited-area models provide a much more accurate simulation of the cyclone, in terms of both intensity and trajectory, 
mainly due to the higher resolution, which does not smooth out the pressure and wind field and allows for a more vigorous cyclone development. An intercomparison among the limited area models also highlights significant differences. In general, the forcing imposed by the global models (that is the sensitivity of the limited area models to the specification of the initial and boundary conditions) is more important for the determination of the trajectory. On the other hand, we find that the intensity of the vortex and its internal structure is a strong function of the specific limited-area model chosen, hydrostatic or non-hydrostatic, with parameterized or explicit convection. The comparison of the present results with those shown in Moscatello et al. (2008a) suggests that a different setup, with a larger external domain and an earlier initial time of the high-resolution simulation (which includes also the formation period of the vortex), can improve the model prediction, although such implementation would be too expensive in terms of computational cost for our specific real-time application. In conclusion, most of the model runs suggest the development of an intense low-pressure system and would have had some value from an operational point of view. However, the detailed prediction of some fields, such as the $10 \mathrm{~m}$ wind speed and the precipitation, would not have provided an accurate forecasting guide.

Sensitivity simulations have been performed with the three limited area models to investigate the mechanisms responsible for the genesis, development and maintenance of the TLC. An orographic cyclogenesis on the southern side of the Atlas Mountains, that was responsible for the generation of a small scale depression. The transition of this vortex into a TLC occurs as a consequence of the surface sensible and latent-heat fluxes and of the latent heat released by convection during the transit of the cyclone across the Strait of Sicily, the Ionian Sea and the southern Adriatic Sea. Of these two mechanisms, the first seems to be more important only in the initial phase, but it still affects the development of the cyclone also in the subsequent period. All our model results support these conclusions.

Acknowledgements. This work was supported by RISKMED project, Programme INTERREG IIIB-ARCHIMED.

Edited by: A. Mugnai

Reviewed by: O. Reale and another anonymous Referee

\section{References}

Billing, H., Haupt, I., and Tonn, W.: Evolution of a hurricane-like cyclone in the Mediterranean Sea, Beitr. Phys. Atmos., 56, 508$510,1983$.

Davolio, S., Buzzi, A., and Malguzzi, P.: High resolution simulations of an intense convective precipitation event, Meteorol. Atmos. Phys., 95, 139-154, 2007.
Emanuel, K.: Genesis and maintenance of "Mediterranean hurricanes", Adv. Geosci., 2, 217-220, 2005, http://www.adv-geosci.net/2/217/2005/.

Fita, L., Romero, R., Luque, A., Emanuel, K., and Ramis, C.: Analysis of the environments of seven Mediterranean tropical-like storms using an axisymmetric, nonhydrostatic, cloud resolving model, Nat. Hazards Earth Syst. Sci., 7, 41-56, 2007, http://www.nat-hazards-earth-syst-sci.net/7/41/2007/.

Homar, V., Romero, R., Stensrud, D. J., Ramis, C., and Alonso, S.: Numerical diagnosis of a small, quasi-tropical cyclone over the western Mediterranean: dynamical vs. boundary factors, Q. J. Roy. Meteor. Soc., 129, 1469-1490, 2003.

Lagouvardos, K., Kotroni, V., Nickovic, S., Jovic, D., and Kallos, G.: Observations and model simulations of a winter sub-synoptic vortex over the Central Mediterranean, Meteorol. Appl., 6, 371383, 1999.

McTaggart-Cowan, R., Bosart, L. F., Gyakum, J. R., and Atallah, E. H.: Hurricane Katrina (2005). Part I: Complex life cycle of an intense tropical cyclone, Mon. Weather Rev., 135, 3905-3926, 2007.

Miglietta, M. M., Davolio, S., Moscatello, A., Pacifico, F., and Rotunno, R. R.: The role of surface fluxes in the development of a tropical-like cyclone in southern Italy, Adv. Sci. Res., 2, 35-39, 2008.

Montgomery, M. T., Nicholls, M. E., Cram, T. A., and Saunders, A. B.: A vortical hot tower route to tropical cyclogenesis, J. Atmos. Sci., 63, 355-386, 2006.

Moscatello, A., Miglietta, M. M., and Rotunno, R.: Numerical analysis of a Mediterranean "Hurricane" over south-eastern Italy, Mon. Weather Rev., 136, 4373-4397, 2008a.

Moscatello, A., Miglietta, M. M., and Rotunno, R.: Observational analysis of a Mediterranean "hurricane" over south-eastern Italy, Weather, 63, 306-311, 2008b.

Pytharoulis, I., Craig, C. G., and Ballard, S. P.: The hurricanelike Mediterranean cyclone of January 1995, Meteorol. Appl., 7, 261-279, 2000.

Rasmussen, E. and Zick, C.: A subsynoptic vortex over the Mediterranean with some resemblance to polar lows, Tellus, 39A, 408425, 1987.

Reale, O. and Atlas, R.: Tropical cyclone-like vortices in the extratropics: observational evidence and synoptic analysis, Weather Forecasting, 16, 7-34, 2001

Rotunno, R. and Emanuel, K.: An air-sea interaction theory for tropical cyclones. Part II: Evolutionary study using a nonhydrostatic axysimmetric numerical model, J. Atmos. Sci., 44, 542 561, 1987.

Skamarock, W. C., Klemp, J. B., Dudhia, J., Gill, D. O., Barker, D. M., Wang, W., and Powers, J. G.: A description of the Advanced Research WRF Version 2, NCAR Technical Note, 468STR, 88 pp., 2005.

Tibaldi, S., Buzzi, A., and Speranza, A.: Orographic cyclogenesis, in: Extratropical Cyclones, edited by: Newton, C., and Holopainen, E. O., Amer. Meteor. Soc., 107-128, 1990. 